\title{
AVELLANEDA Y BÉCQUER: DEL MAGISTERIO FEMENINO A LA BIOGRAFÍA SENTIMENTAL
}

\author{
AVELLANEDA AND BECQUER: FROM WOMEN AUTHORITY \\ TO SENTIMENTAL BIOGRAPHY
}

Isabel Navas Ocaña

Universidad de Almería. Almería, España

minavas@ual.es

\begin{abstract}
Resumen: La relación de Bécquer con algunas célebres contemporáneas suyas suscitó muy pronto el interés de la crítica. Reconocidos becquerianistas como Rubén Benítez y Joseph Gulsoy no dudaron en señalar entre las fuentes de las Leyendas los relatos de Cecilia Böhl de Faber y de Gertrudis Gómez de Avellaneda. De hecho, La ondina azul, una de las leyendas más famosas de Avellaneda, es considerada la fuente de Los ojos verdes y El rayo de luna de Gustavo Adolfo Bécquer. Además, las Rimas fueron desde finales del XIX motivo de encendidos debates en torno a sus posibles vínculos con la poesía de Rosalía de Castro y de Carolina Coronado. No obstante, la influencia ejercida por Gertrudis Gómez de Avellaneda sobre la prosa de Gustavo Adolfo Bécquer, a pesar de haber sido analizada, necesita desde mi punto de vista una revisión, porque prejuicios de género han determinado a menudo las valoraciones críticas de la obra de Bécquer y de Avellaneda. Además, examinaremos las relaciones personales que mantuvieron Bécquer y Avellaneda, y mostraremos cómo este aspecto de sus biografías ha determinado también la valoración que sus leyendas han recibido de la crítica.
\end{abstract}

Palabras clave: Gertrudis Gómez de Avellaneda, Gustavo Adolfo Bécquer, literatura española del siglo XIX, teoría de la literatura, crítica literaria, estudios de género, feminismo.

Abstract: Becquer's relationship with some famous contemporary women writers soon attracted the interest of critics. Important becquerianistas such as Rubén Benítez and Joseph Gulsoy did not hesitate in pointing the stories of Cecilia Böhl de Faber and Gertrudis Gómez de Avellaneda among the sources of Bécquer's Leyendas. In fact, La ondina azul, one of the most famous Avellaneda's tale, is considered the origin of Bécquer's Los ojos verdes and El rayo de Luna. In addition, the celebrated Rimas were from the late nineteenth century cause of heated debate about their possible links with the poetry of Rosalía de Castro and Carolina Coronado. However, the influence exerted by Gertrudis Gómez de Avellaneda on Gustavo Adolfo Bécquer' 
prose, despite having been also analyzed, in my view needs revision, because gender bias often have determined critical views about both Avellaneda y Bécquer. Furthermore we will examine personal relationships that kept Avellaneda and Bécquer and how this aspect of their biographies have also determined the assessment that their tales received by critics.

Keywords: Gertrudis Gómez de Avellaneda, Gustavo Adolfo Bécquer, nineteeth century spanish literature, literary theory, literary criticism, gender studies, feminism.

Recibido: 14.12.2015. Aceptado: 15.05.2016.

Q

UIZÁs SEA LA AUTOBIografía de Gertrudis Gómez de Avellaneda la que ha suscitado en los últimos años una mayor atención (Suárez-Galbán, 1980; Catena, 1989; Catelli, 1991; Arriaga Flórez, 2001; Ferrús Antón, 2003 y Torras, 2003), aunque las novelas Dos mujeres y Sab han interesado también mucho al feminismo, tanto por su carácter reivindicativo como por la identificación entre mujer y esclavo, identificación que propicia el encuentro con los planteamientos de la crítica postcolonial (Gutiérrez de la Solana, 1981; Guerra Cunningham, 1985; Kirkpatrick, 1989 y 1990; Ayala, 1998; Pastor, 2002 y 2004; Ferrús Antón, 2004 y Barreto, 2006). Además se han examinado otros aspectos de la obra de Avellaneda como el teatro

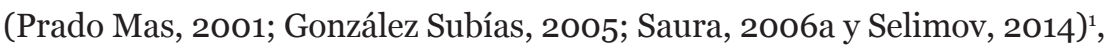
la poesía (Albin, 2002), las traducciones (Saura, 2006b), los prólogos (Romero, 2014) y las colaboraciones en prensa, desde "La dama de gran tono" que apareció en 1843 en el Album del bello sexo o Las mujeres pintadas por sí mismas (Albin, 2007), pasando por "Capacidad de las mujeres para el gobierno”, publicado en La Ilustración: Álbum de las damas (1845) (Albin, 2000), y sobre todo el Álbum Cubano de lo Bueno y de lo Bello, la revista que fundara en su Cuba natal en 1860, en concreto la serie de artículos titulada "La mujer” y "Galería de mujeres célebres" (Santos, 1981; Picón Garfield, 1992; Albin, 1995; Scott, 1997 y Pastor, 1999). El debate sobre la condición de poeta o de poetisa de la Avellaneda, que inauguró A. Ferrer del

\footnotetext{
${ }^{1}$ María Prado Mas se ha encargado de la edición contemporánea del drama bíblico Baltasar y de la comedia La hija de las flores en la colección de literatura dramática de la Asociación de Directores de Escena (2000). Y Concha Fernández Soto ha editado el volumen Errores del corazón y otras comedias (2008).
} 
Río en 1846 y en el que Carolina Coronado tuvo un papel destacado, ha sido también objeto de examen en los últimos años (Rodríguez Gutiérrez, 2014).

Ahora bien, la posible influencia que la escritora cubana ejerciera sobre Gustavo Adolfo Bécquer, el poeta canónico del romanticismo español, a pesar de haberse analizado, necesita a mi juicio una revisión. Es cierto que la relación de Bécquer con algunas célebres contemporáneas suyas concitó muy pronto el interés de la crítica. Reconocidos becquerianistas como Rubén Benítez y Joseph Gulsoy no dudaron en señalar entre las fuentes de las Leyendas los relatos de Cecilia Böhl de Faber y de Gertrudis Gómez de Avellaneda. Además, las Rimas fueron desde finales del XIX motivo de encendidos debates en torno a sus posibles vínculos con la poesía de Rosalía de Castro y de Carolina Coronado (Navas Ocaña, 2011: 205-229). La suerte que ha corrido la obra de Bécquer tras estos análisis de sus afinidades con las escritoras del XIX ha sido diversa, aunque con un saldo siempre positivo para el sevillano, que ha visto como, a pesar de y precisamente gracias $a$ la influencia, y hasta la imitación de algunos motivos empleados primero por Gertrudis Gómez de Avellaneda, Carolina Coronado y Rosalía de Castro, su fama se ha incrementado y se ha reforzado su condición de escritor canónico. Veamos más detenidamente el caso de Avellaneda y, en relación con él, el de Böhl de Faber, puesto que a ambas se las considera antecedentes de las celebérrimas Leyendas becquerianas.

Rubén Benítez fue de los primeros en considerar los relatos folklóricos de Cecilia Böhl de Faber, junto con las narraciones históricas en verso de Zorrilla, como uno de los modelos fundamentales de dichas leyendas ${ }^{2}$. La ingenuidad de las historias, la pretensión de realismo, "el fondo de moralidad edificante", así como la temática religiosa, sobre todo "la devoción popular”, son, en su opinión, los principales aspectos que Bécquer toma de los cuentos de Böhl de Faber:

${ }^{2}$ Benítez es de los primeros en señalar vínculos entre Bécquer y Cecilia Böhl de Faber si exceptuamos a Rica Brown, que ya en 1963 puso en relación La gaviota y el relato de F. Moreno Godino sobre Antonia, la niña a la que Bécquer conoció en uno de sus paseos en barca hasta la isla del Guadalquivir. Dice Rica Brown: "Situación curiosa, parecida, además, poco más o menos a la que sirviera a Fernán Caballero para su primera novela: La gaviota" (1963: 148). 
(...) Los modelos más evidentes de ese conjunto de narraciones provienen de Fernán Caballero y de Zorrilla. Zorrilla, sobre todo, cuando es relato en verso.

Los que siguen el modelo de Fernán Caballero, eslabonan en historias originales, sorprendentemente ingenuas en su concepción, y con un fondo de moralidad edificante, elementos hallados en el folklore español. Pretenden de realismo en cuanto aseguran la fidelidad del relato con la tradición, la existencia real de los personajes y la trascripción exacta del habla popular.

(...) Las leyendas de contenido religioso se asocian también a Fernán Caballero o a Zorrilla según se destaquen en ellas las formas ingenuas de la devoción popular o el misterio de los milagros cristianos (1971: 194-195).

Benítez precisa en otro lugar que Bécquer hereda de Zorrilla "la descripción arqueológica" y la expresión de "lo sublime terrorífico", mientras que todo lo que tiene que ver con la "verosimilitud realista" procede de Cecilia Böhl de Faber³, a quien el poeta ya había expresado su reconocimiento en el prólogo que escribió para La soledad de Augusto Ferrán. Aquí recuerda Bécquer la importante labor de rescate de las canciones populares que realizaron tanto Fernán Caballero como Antonio Trueba ${ }^{4}$. Y este

3 “Zorrilla aprende la lección de Espronceda. Difunde el género y lo desarrolla en todas sus posibilidades; hasta tal punto que en 1862, Coll y Vehí define la leyenda literaria teniendo sólo en cuenta la narración histórica en verso al modo de Zorrilla. Cuando Bécquer aparece en la escena española este tipo de leyenda está en vías de extinción. Ha surgido en cambio el relato folklórico de Fernán Caballero, en que no se trata ya de utilizar un asunto tradicional, o inventar otro, para ambientarlo en un pasado histórico, sino de auténticos cuentos populares provenientes de la tradición oral, transcriptos con técnicas fidedignas, sin los agregados de la fantasía del recopilador. Por otra parte, gran número de repertorios han puesto a disposición de los escritores los modelos del cuento popular, a menudo sobre asuntos maravillosos, propios de la tradición europea. Bécquer recrea el género: mantiene cierta deuda con la leyenda anterior, las técnicas de descripción arqueológica, las expresivas de lo sublime terrorífico; tiende sin embargo a la verosimilitud realista, a respetar la economía y los modos del relato popular y, sobre todo, a crear un ambiente de maravilla lírica, similar al de los cuentos de hadas. Campillo, amigo de Bécquer, debe así replantearse la definición del género en su tratado de Retórica: distingue ahora la leyenda en verso y en prosa, y da como modelo, entre otros, a su amigo" (Benítez, 1974: 22-23).

${ }^{4}$ Dice Bécquer: “(...) estas canciones se admiran, es verdad, se aplauden, se repiten de boca en boca. Trueba las ha glosado con una espontaneidad y una gracia admirables; Fernán Caballero ha reunido un gran número en sus obras; pero nadie ha tocado ese género para elevarlo a la categoría de tal en el terreno del arte. A esto es a lo que aspira el autor de La soledad" (Bécquer, 1995, II: 572-573). 
reconocimiento da pie a que la crítica posterior cite entre las fuentes de las Leyendas a Cecilia Böhl de Faber. De hecho, Ricardo Navas Ruiz, editor contemporáneo de las obras de Bécquer, y Ángel Esteban, estudioso de sus narraciones, no han dudado en repetir lo que ya había sido dicho por el propio Bécquer y corroborado por Rubén Benítez ${ }^{5}$. No hay, por tanto, en este caso ninguna reticencia a reconocer como antecedente directo, como fuente, como influencia, a una mujer. No obstante, Rubén Benítez, como buen becquerianista, pondera los méritos de Bécquer e insiste en que éste supera con holgura a sus modelos y los mejora ostensiblemente:

Como todo escritor auténtico, Bécquer supera el denominador común de los relatos legendarios de su tiempo a fuerza de talento expresivo. Los asuntos más comunes encubren en él una temática de humana permanencia. (...) Leer sus leyendas es acompañar al narrador en una aventura misteriosa. (...) Como ocurre con los posibles modelos populares de sus rimas, Bécquer va así, en las leyendas, más allá de las tradiciones que recibe. No es el caso de transmitirlas, ni tampoco el de imitarlas, sino el de renovar a cada paso el carácter de la creación legendaria. No repite consejas del pueblo: se hace pueblo en la tarea de narrarlas (1971: 197-200).

Aunque Benítez es sumamente respetuoso y no le cuelga a Cecilia Böhl de Faber el sambenito de "escritora menor", ni se dedica a cantar las alabanzas de la prosa becqueriana por contraste con la de Cecilia Böhl de Faber, como ocurrirá con Carolina Coronado y con Rosalía de Castro (Navas

${ }^{5}$ En la Introducción al tomo II de las Obras completas de Bécquer, dice Navas Ruiz: "El sevillano tiene entre sus precedentes la novela histórica de tema medieval, las leyendas de Zorrilla, los cuentos de Hoffmann y posiblemente los de Poe. Podría añadirse el costumbrismo romántico y el color popular de Fernán Caballero o Antonio Trueba” (1995, II: IX). $\mathrm{Y}$ en la introducción al volumen integrado por el Libro de los gorriones, las narraciones y "escritos varios", Navas Ruiz vuelve a insistir: "Por otro lado, su interés por el folklore le llevó a explorar directamente la tradición y la conseja, en lo que quizá no ha sido ajeno el ejemplo de Fernán Caballero y Antonio Trueba" (2005: 29). Por su parte, Ángel Esteban le reconoce a Cecilia Böhl de Faber el mérito de haber sido la primera en realizar una «selección con rigor científico» de los materiales procedentes de la tradición popular: "La primera selección con rigor científico fue hecha en 1859, por Fernán Caballero, bajo el título Cuentos y poesías populares andaluces, publicada en Sevilla, en la imprenta de la Revista Mercantil. A partir de ahí los investigadores son más certeros y profusos" (Esteban, 2007: 28). Y añade: "Precisamente de Fernán Caballero y sus relaciones aprende el sevillano el modo de introducir relatos tradicionales y motivos folklóricos en el texto ficticio" (2007: 21). 
Ocaña, 2011: 205-229), lo cierto es que le otorga a Bécquer una primacía que vendrá a reforzar la situación privilegiada del poeta en el canon de la literatura decimonónica española. Empezamos ya, pues, a ver colocado a Bécquer un peldaño más arriba en la escala del valor literario que sus contemporáneas, que las escritoras de su tiempo.

Y Gertrudis Gómez de Avellaneda no va a ser en este sentido una excepción. Cuando J. Gulsoy llama la atención en 1967 sobre las grandes coincidencias entre La ondina del lago azul de Avellaneda y Los ojos verdes y El rayo de luna de Bécquer, lo hace no sin puntualizar a cada paso que Bécquer "ha superado a su modelo" con creces (1967: 101). Se trata, por tanto, de la misma estrategia de lectura que acabamos de analizar en relación con Cecilia Böhl de Faber, aunque en esta oportunidad se abunda más tanto en las semejanzas, que son muchas, como en los numerosos errores de Avellaneda que Bécquer ha logrado con gran acierto corregir.

La ondina del lago azul se publicó entre el 18 y el 25 de julio de 1860 en el Diario de la Marina de La Habana. Los ojos verdes apareció el 15 de diciembre de 1861 en El Contemporáneo. Gulsoy supone que "Bécquer leería la narración de la Avellaneda en un ejemplar de dicho periódico cubano, que le llegaría a las manos en Madrid" (1967: 97). La semejanza temática entre las dos leyendas es muy grande. Si La ondina del lago azul tiene por protagonista a un joven poeta, Gabriel, que se enamora de la ondina que habita las aguas azules de un lago pirenaico, Los ojos verdes relata la historia de Fernando, también enamorado de una ondina, moradora de una fuente conocida con el nombre de Fuente de los Álamos y sita en las inmediaciones del Moncayo. En las dos leyendas los jóvenes hablan a sus servidores, Lorenzo en un caso e Íñigo en el otro, de la misteriosa presencia femenina que los inquieta -los parlamentos y las descripciones de las ondinas son muy parecidas-, y para más señas, tanto Gabriel como Fernando tienen el mismo final, hundiéndose en las aguas en busca de sus amadas ${ }^{6}$. Para

${ }^{6}$ En 1997, Benito Varela Jácome trató también esta cuestión de las semejanzas entre las dos leyendas, coincidiendo en lo fundamental con Gulsoy, a quien sin embargo no cita. Varela Jácome se limita a señalar que "varios estudios críticos confirman la anticipación de Gertrudis Gómez de Avellaneda a las Leyendas de Gustavo Adolfo Bécquer" (1997: 116), sin aclarar de qué estudios se trata. Supongo que se refiere a Gulsoy y también a Rexach, cuyo artículo "Conexiones entre las leyendas de Avellaneda y Bécquer", sobre el que volveremos más adelante, se publicó en 1987. Pues bien, según Varela Jácome, La ondina del lago 
Gulsoy está muy clara "la identidad del asunto de La ondina del lago azul con el de Los ojos verdes" (1967: 98). Ahora bien, lo que en Avellaneda era una leyenda de cierta extensión, aproximadamente "unas treinta páginas", y por ello más bien "difusa”, con Bécquer se convierte en una narración de "estructura densa, sobria de hechos”, que apenas alcanza las cinco páginas, y que está construida sólo a partir de dos escenas de La ondina azul: "el parlamento entre el protagonista y el servidor" y "la entrevista de aquél con la ondina" (1967: 98). De hecho, Gulsoy sostiene que los también evidentes contactos de El rayo de luna con La ondina azul proceden precisamente de aquellos "pasajes que quedaron sin contribuir a Los ojos verdes", que Bécquer no utilizó para Los ojos verdes. La tesis de Gulsoy es que el sevillano refundió la leyenda de Avellaneda en dos versiones diferentes, Los ojos verdes y El rayo de luna, y para apoyar esta hipótesis recurre no sólo a las coincidencias temáticas sino también a la cronología:

Nuestra opinión de que Bécquer concibiera el mismo asunto en dos versiones, de la manera indicada, parece todavía más plausible, si consideramos la fecha de publicación de las dos leyendas. El rayo de luna, publicado en El Contemporáneo el 12 y el 13 de febrero de 1862, fue escrito inmediatamente después de Los ojos verdes (Este, como hemos indicado, es del 15 de diciembre de 1861). Vale notar además que lo de construir la leyenda en torno a una mujer imaginada en un rayo de luna, debió de ocurrírsele a Bécquer de la lectura del siguiente pasaje del cuento de la Avellaneda, donde Gabriel comunica a Lorenzo en qué medio imagina ver a la mujer aspirada: "Yo la veo en los risueños albores de la aurora... a la deslumbradora claridad del astro del día, como a los destellos apacibles de la luna”. Quizá no esté de más agregar todavía que la escena de la barca en que va la mujer ideal se encuentra sólo en $E l$ rayo de luna y La ondina del lago azul (1967: 105).

Gulsoy cree que en La ondina azul Avellaneda "falló en la estructuración del asunto", en primer lugar porque "simuló narrar una historia real, oída por ella misma a un testigo de los hechos”, en un intento, muy desafortunado según Gulsoy, de proporcionar veracidad a su relato, que habría

azul y Los ojos verdes coinciden en la descripción de las ondinas, en el encantamiento de que son objeto Fernando y Gabriel por parte de ellas, y en el "final irreversible" de ambos (1997: 118). 
funcionado mejor, por ser la protagonista una "mujer sobrenatural", "en la esfera de lo fantástico" y en un tiempo remoto, legendario, de señores feudales, como el de Los ojos verdes (1967: 101-102). Y en segundo lugar, Avellaneda falla al terminar otorgándole a su ondina la identidad de "una bella mujer aventurera", porque de esta forma Gabriel aparece "como un simple y una pobre víctima más que como un poeta romántico soñador", y todo acaba reduciéndose «a una burla cruel» que pierde mucho en "encanto poético y natural gracia” (1967: 102)7. La originalidad de Bécquer quedaba así a salvo de toda duda:

Es evidente que La ondina del lago azul fue decididamente la fuente inmediata de Los ojos verdes, y que le había proporcionado no sólo su asunto sino además las nociones básicas de su estructura y concepción. Cabe subrayar que no se trata aquí de una mera familiaridad de Bécquer con la leyenda de la Avellaneda, sino de una refundición de la misma en una nueva forma. Por lo visto, Bécquer fue atraído por el tema de amor entre un joven poeta y una mujer sobrenatural, tema que llevaba grandes posibilidades artísticas, pero que en la versión de la Avellaneda no quedaba debidamente desarrollado, o mejor dicho, el tratamiento de ésta permitía mucha mejora todavía. Nuestro autor ha superado a su modelo precisamente en la estructura y elaboración artística, y hay que ver su originalidad en estos aspectos (1967: 101).

No obstante, los defectos que Gulsoy observa en La ondina azul bien podrían considerarse virtudes a poco que examinemos los criterios de enjuiciamiento que han conducido a semejante adversa conclusión. Que Avellaneda haya desarrollado más ampliamente el asunto -sus treinta páginas frente a las cinco de Bécquer- es, según Gulsoy, un error que desdibuja la

${ }^{7}$ Sigue Gulsoy en este punto a Leopoldo Augusto Cueto, quien en "Observaciones acerca de algunas leyendas y novelas de la señora doña Gertrudis Gómez de Avellaneda” ya había mostrado su disgusto por "la explicación dada después de terminada la leyenda, de las causas prosaicas y tangibles que han ocasionado el alucinamiento apasionado de Gabriel. De repente, y con cierta desagradable violencia, se desvanece la ilusión que ha de quedar necesariamente en la imaginación del lector, después de los mágicos cuadros de la leyenda. Gabriel no es ya el mancebo instruido, artista, algo misántropo, que huye de la realidad prosaica de la vida, prendado únicamente del ideal que le forjan a un tiempo su enardecida fantasía y los inefables y misteriosos hechizos de la naturaleza. ¿Qué importa al lector saber que la ondina no es la creación aérea y conmovedora de un cerebro juvenil y enfermizo, sino una coqueta de París, que se burla del sandio aldeano?” (Cueto, 1871: 406). 
historia, más concentrada y sobria en Bécquer, quien opta por refundirla en dos leyendas diferentes de menor extensión. Sobriedad y concentración son en este caso las varas de medir que Gulsoy maneja para cantar las excelencias del sevillano. Pero son sólo eso, varas de medir empleadas con el interesado fin de encumbrar a Bécquer por encima de su modelo. Y si no ¿̇por qué lo breve ha de ganarle aquí la partida a lo más extenso? ¿No habría mayor riqueza de datos y de matices en una narración más larga? ¿Si quisiéramos ponderar el mérito de Avellaneda por encima del de Bécquer no bastaría con decir que su relato es más completo, más rico, más acabado? Y todo ello sin perder de vista que el principal argumento para ponderar dicho mérito es el de la anticipación: que Avellaneda se anticipa a Bécquer, que le precede en el tratamiento del asunto.

En cuanto a los recursos de los que Avellaneda se vale para proporcionarle un aire de verosimilitud a su historia, y que tanto disgustan a Gulsoy, se podrían hacer también algunas puntualizaciones. Gulsoy inclina la balanza del lado de lo fantástico y lo sobrenatural, arguyendo que con Bécquer la historia sale ganando, es más "poética», al ser protagonizada por una mujer fantasmal y situarse en una ambientación medieval. Avellaneda, en cambio, había optado decididamente por el presente y por el realismo: su protagonista es una mujer de carne y hueso, contemporánea, de quien Avellaneda tiene conocimiento por un testigo presencial de los hechos. ¿Por qué a Gulsoy y a su predecesor, Leopoldo Augusto Cueto, les parece mejor la opción de Bécquer? Ante todo, por el papel que el personaje masculino asume en uno y otro caso. Con Avellaneda se trata simplemente de un amante burlado, de un "sandio aldeano", como apunta Cueto. Gracias a Bécquer, sin embargo, el burlado se transmuta en un soñador, en un idealista. Es el afán de dejar bien parado al héroe masculino, lo que motiva en última instancia las conclusiones de Gulsoy, y también las de Cueto. Son prejuicios de género los que les impulsan a preferir el soñador al necio burlado.

Sin embargo, Evelyn Picón Garfield ha valorado muy positivamente el hecho de que la ondina de Avellaneda sea una mujer frívola, por lo que esto tiene de trasgresión, de subversión del ideal femenino imperante en la época, y les ha reprochado a Cueto y a Gulsoy la ceguera de no haber comprendido, de no haber apreciado, dicha trasgresión: 
En sus comentarios sobre "La ondina del lago azul", ni Cueto ni Gulsoy toman en cuenta el contexto de la obra entera de Gómez de Avellaneda, y tal vez por eso no se dan cuenta de que la autora está subvirtiendo el ideal poético masculino de la mujer por medio de la materialización y la vulgarización de tal imagen. En el proceso subversivo hace aparecer al poeta, ingenuo iluso y engañado (1993: 177).

Y más recientemente $\mathrm{M}^{\mathrm{a}}$ de los Ángeles Ayala le ha quitado importancia al hecho de que la ondina se revele como una dama coqueta, porque el personaje de Gabriel cree en lo que ve, lo que lo convierte en un "mártir del amor" en la tradición de la literatura cortesana:

No importa que al final del relato Lorenzo descubra a la propia autora que en realidad nunca existió la misteriosa ondina y que todo fue el fatal resultado de una cruel diversión ideada por una frívola dama que en aquel entonces pasaba sus vacaciones estivales en esos parajes. Lo cierto es que Gabriel cree en aquello que vive y siente, y eso le convierte en un mártir de amor, uno más de la larga nómina de enamorados enfebrecidos que desciende de la fructífera tradición del amor cortés en la que el ritual erótico y los sentimientos apasionados confluyen admirablemente (2006: 20).

En suma, criterios tan aparentemente neutros como la brevedad, lo legendario, lo fantástico, lo poético, esconden, como hemos demostrado, prejuicios de género, prevenciones en contra de las mujeres, y se utilizan para otorgarles a las escritoras una calificación siempre inferior a la de sus homólogos masculinos. Gulsoy reconoce la deuda de Bécquer con Avellaneda pero se prodiga tanto en la relación de los defectos de La ondina azul superados por Bécquer, insiste con tanta vehemencia en la maestría con la que Bécquer refunde la leyenda de Avellaneda depurando sus errores, que en última instancia poco importa que Avellaneda sea o no la fuente de Bécquer porque esta circunstancia no le reporta a la cubana ningún beneficio, no la hace merecedora de ninguna prebenda, de ningún elogio. Al contrario, haberse cruzado, tan claramente al parecer, en el camino a la gloria de Bécquer la ha terminado por hundir a ella algunos escalones más abajo en el escalafón del mérito literario.

No obstante, y como indica el propio Gulsoy, "interesaría saber si la Avellaneda había tenido modelo para La ondina del lago azul" (1967: 105), 
porque ello nos va a permitir analizar con una perspectiva más amplia y más rica el tema de la influencia sobre el poeta sevillano. Leopoldo Augusto Cueto encontró pronto semejanzas con Rusalka de Puchkin (1819) y con Undine de E. T. A. Hoffmann (1816), leyendas a su juicio muy inferiores a la de Avellaneda, excepto en lo que respecta al desvelamiento de la identidad terrenal de la ondina ${ }^{8}$. Cotarelo y Mori menciona también a Puchkin y a Hoffmann, observa en La ondina del lago azul el mismo carácter "alado y vaporoso" de las leyendas de Walter Scott, y no duda en proclamar, como hiciera Cueto, la primacía de Avellaneda respecto a sus predecesores ${ }^{9}$. Obsérvese que ni Cueto ni Cotarelo argumentan esta primacía, simplemente la afirman, que no entran en detalles sobre los aspectos en los que Avellaneda aventaja a Puchkin o a Hoffmann, limitándose a pronunciar un juicio de corte nacionalista, cuyo fin no parece otro que el de ensalzar la literatura patria frente a lo extranjero. En el caso de J. Gulsoy, la relación de fuentes incluye Die Undine de F. de la Motte Fouqué, Der Fischer de Goethe, Die Lorelei de Heine, los cuentos de Hoffmann y especialmente el cuento Inès de las Sierras (1837) de Charles Nodier, cuyo protagonista, Sergy, tiene mucho que ver con el Gabriel soñador de La ondina del lago azul' ${ }^{10}$ Gul-

\footnotetext{
8 "Púchkin, el gran poeta ruso, escribió una leyenda fantástica, titulada Rusalka, que es la ondina de las consejas moscovitas; leyenda por cierto muy inferior a La Ondina del lago azul. Pero se guarda bien de dar explicación alguna de las cosas sobrenaturales que en ella pasan. Lo mismo hace Hoffmann, gran maestro de la literatura fantástica. Dar la clave de la ilusión, es disiparla" (Cueto, 1871: 406).

9 "Es una lindísima leyenda que parece escrita por Walter Scott, tan alada y vaporosa y a la vez interesante nos la ofrece la autora. No tiene nada de original, porque repetidas veces se ha contado la anécdota del joven soñador, enamorado de una visión que la luz de la luna, los vapores de un lago o un río, y más que nada su propia locura forma y que le arrastra al suicido en aquel mismo elemento que creen ser la mansión de la mujer ideal. Pero ni Púchkin en su Rusalka, ni Hoffmann, igualan a nuestra escritora en esta preciosa leyenda". Cotarelo publicó "La Avellaneda y sus obras. Ensayo biográfico y crítico" entre 1928 y 1930 en el Boletín de la Real Academia Española. El fragmento aquí citado apareció en el tomo XVII, Cuaderno LXXXI, 1930, p. 31. Luego lo editaría como libro en 1930.

10 "(...) puede ser que se inspirara más bien en la lectura de una de tantas baladas o poemas de tema de ninfas y espíritus del agua (pensamos en Die Undine de F. de la Motte Fouqué, Der Fischer de Goethe, Die Lorelei de Heine, etc.), quizá no en su original alemán, sino a través de las traducciones francesas y aun españolas. Ya se sabe que hacía imitaciones de las obras de autores franceses. Por otra parte, el joven protagonista que se entrega a ensueños en el seno de la naturaleza tampoco es una creación original de la Avellaneda. Tales personajes aparecen en algunos cuentos de Hoffmann, y más notable todavía, en el cuento fantástico Inés de las Sierras (1837) de Charles Nodier. Uno de los protagonistas de dicho relato, Sergy, nos recuerda a Gabriel, por ser de temple poético, sentimental, un
} 
soy cree que Bécquer se valió precisamente de Inès de las Sierras como modelo para su leyenda El beso (1967: 106). La crítica reciente ha añadido otros nombres a la lista de las posibles fuentes de inspiración de Avellaneda. María de los Ángeles Ayala menciona El caballero Cifar y el poema "La fuente de la Mora" de Quintana ${ }^{11}$, y Ángeles Ezama Gil, que relaciona la aparición de la figura de la dama del lago con la materia de Bretaña del ciclo artúrico, cita además "Maitagarri” de José María de Goizueta (1856) y la ópera de Rossini La donna del lago (1819), basada en La dama del lago (1810) de Walter Scott ${ }^{12}$. Ni los ensayos de Cueto y Cotarelo, ni los de Ayala y Ezama, más próximos cronológicamente, entran de lleno en la cuestión de las influencias ${ }^{13}$. Al contrario, se limitan a ofrecer una relación de títulos,

músico, y por aspirar a otro mundo mejor, y por tener a una mujer ideal soñada. Sergy, lo mismo que Gabriel se enamora de un ser sobrenatural, el fantasma de una mujer. El cuento de Nodier tiene además una secuela, en que se descubre que la mujer fantástica es real, como la de la Avellaneda. Es probable que nuestra autora concibiera el argumento de su leyenda en sus recuerdos de la lectura de obras como la de Fouqué, o más bien, la de Nodier, y que le diera forma en su imaginación en el ambiente poético de los Pirineos, durante su visita alli”" (Gulsoy, 1967: 105-106).

${ }_{11}$ “(...) es probable también que conociese parte de la tradición literaria existente sobre dicho tema, una tradición que se dilata en la literatura española desde una historia incluida en El caballero Cifar hasta el poema "La fuente de la Mora" de Quintana y que está presente en variadas obras extranjeras, como la Ondine de La Motte-Fouqué (1811), Lore Lay de Brentano (1801), Lorelei de Heine (1824), Das Käthchen von Heilbronn (1808) de Kleist, por no mencionar las adaptaciones a óperas del tema de Loreley debidas a Lachner (1846) y Wallace (1850) o de la ópera de Hoffmann titulada, precisamente, La Ondina (1814). No debemos olvidar tampoco las leyendas y tradiciones orales que, especialmente en el norte de España, recogen versiones diferentes sobre misteriosas mujeres que seducen a los paseantes y los arrastran a los abismos o a las profundidades del agua. Las xanas o lavanderas de Asturias, las lamias, lamiñas o lamiñaku del País Vasco, las gojes o dones d'aigua de Cataluña y esta misma figura en Galicia, representan un claro ejemplo de la difusión de este motivo de larga raigambre folklórica y popular que muy bien pudo inspirar a Gertrudis Gómez de Avellaneda" (Ayala, 2006: 14).

12 "La dama del lago tiene hondas raíces en el folclore europeo, sobre todo germánico: su aparición en la literatura hay que vincularla a la materia de Bretaña del ciclo artúrico; en la contemporaneidad ha sido glosada en textos como La dama del lago (1810) de Walter Scott, Ondina del barón de La Motte-Fouqué (1811), Rusalka de Puchkin (1819), "Maitagarri" de José María de Goizueta (1856) y la leyenda becqueriana "Los ojos verdes" entre otros. El asunto ha inspirado también las óperas de Hoffmann Online 81816) y de Rossini La donna del lago 81819), basada esta última en el poema de Walter Scott" (Ezama Gil, 2011: 336).

${ }^{13}$ Ángeles Ezama sí señala la coincidencia de Avellaneda y Bécquer en el significado que le otorgan al término tradición. Según Ezama, las denominaciones de leyenda y de tradición no las utiliza Avellaneda "de modo indistinto, como parece habitual en el período romántico, sino que apuesta claramente por la tradición, sobre todo cuando estas narracio- 
que presentan una evidente comunidad temática basada en la figura de la dama del lago, y no van más allá. Pues bien, estas relaciones tienen, en mi opinión, un efecto contraproducente en la determinación del influjo de la Avellaneda sobre Bécquer, porque éste se difumina y acaba perdiéndose en el fárrago de un sinfín de nombres, que se remontan además muy atrás, a la literatura medieval, y que hacen de Bécquer no el imitador de un modelo sino simplemente el eslabón de una tradición. Esto es lo que sucede en el ensayo de Pilar Vega Rodríguez, titulado significativamente "Todas las hadas tienen su lago: geografía fantástica de la leyenda literaria en el Romanticismo español" (2009). Vega Rodríguez, que trae muy atinadamente a colación la novela de George Sand Les dames vertes ${ }^{14}$, publicada en 1857 , tres años antes que el relato de Avellaneda, más que hablar de influencias prefiere hacerlo de similitudes, similitudes que en el ámbito hispánico circunscribe a un corpus de textos muy concreto, integrado por el romance de Quintana "La fuente de la mora", La ondina del lago azul de Avellaneda, Los ojos verdes de Bécquer y La Victoria de la Virgen (1850) de Víctor Balaguer. De hecho, el final trágico de Fernando en Los ojos verdes lo relaciona, lo hace depender, no del final trágico del Gabriel de La ondina del lago azul, sino del poema de Quintana, teniendo además buen cuidado de dejar claro que no se trata de una "imitación", sino de un "esquema narrativo" que viene de lejos, del que Bécquer se vale al igual que Avellaneda:

La similitud de ambos pasajes nada tiene que ver con la imitación o el seguimiento literal. El romancillo de Quintana era tan popular que probablemente había llegado a construir un esquema narrativo, y Bécquer no hace sino utilizar un molde que es ya un dispositivo estable en la construcción del tema del amor entre el mortal y la ondina. Es la misma estampa que concluye el desgraciado amor de Gabriel en la leyenda de Avellaneda. A la orilla del lago, la flauta caída en el suelo, es prueba del irrevocable final (Vega Rodríguez, 2009).

$\overline{\text { nes aparecen insertas en los relatos de viaje, tratando de ilustrar el carácter y costumbres }}$ de los pueblos recorridos mediante la relación de historias profundamente enraizadas en ellos", como sucede en La ondina del lago azul (2011: 335). Y este concepto de tradición es el mismo del que Bécquer se vale en la Historia de los templos de España, en las Cartas desde mi celda y, por supuesto, en sus leyendas (2011: 337).

${ }^{14}$ La obra de Avellaneda que más se ha relacionado con George Sand ha sido, sin embargo, Dos mujeres, aunque la propia Avellaneda negara la relación (Carlos, 1968: 190). 
Obsérvese que la cronología desaparece, que se obvia la precedencia temporal de un relato sobre otro. Es más, el de Bécquer, que es posterior, aparece aquí en primer lugar, antes que el de Avellaneda, saltando por delante de él, para ir a una fuente, el poema de Quintana, con el que sólo tiene una relación temática. Precisamente porque es un poema y no una leyenda, las similitudes en el desarrollo de la historia, al tratarse de dos moldes literarios diferentes, no son tan acusadas como las existentes con La ondina del lago azul de Avellaneda. Retrotraer el origen de la leyenda de Bécquer a los versos de Quintana, o a una leyenda anterior como hará Hugh Harter ${ }^{15}$, no clarifica la relación entre La ondina del lago azul y Los ojos verdes, al contrario la ensombrece, la apaga. $Y$ el inventario de textos de otras literaturas, e incluso de otros ámbitos artísticos como la ópera o el teatro, por muy bien pergeñado que esté y por erudito que parezca, se convierte en una estrategia de lectura que difumina la influencia de Avellaneda sobre Bécquer, que no la reconoce, que acaba ocultándola ${ }^{16}$.

Por otra parte, ha habido quien, a partir de las semejanzas de las leyendas de Bécquer con las de Avellaneda, ha concebido una sugestiva ficción sobre una posible historia de amor entre los dos poetas, convirtiéndose así la Avellaneda en esa misteriosa mujer, que trajo durante décadas de cabeza a todo el becquerianismo, a la que Bécquer habría amado con locura y que le habría destrozado el corazón justo en los meses que mediaron entre el final del romance de salón con Julia Espín y la boda con Casta Esteban (Navas Ocaña, 2011: 44-73). Sostiene esta hipótesis Rosario Rexach, quien, antes de plantear abiertamente la posibilidad de un romance entre Bécquer y Avellaneda, se demora en la relación de las similitudes entre las leyendas de ambos. El miedo originado por un intenso sentimiento de culpa es el

15 "The Water Nymph of the Blue Lake" is, as already mentioned, a variation of the wellknown legend on which Gustavo Adolfo Bécquer based his more famous version entitled "Los ojos verdes" (“The Green Eyes"). Up to a certain point, both authors' versions are quite close" (Harter, 1981: 164).

${ }^{16}$ En 2005 Juan Antonio Molina Foix preparó para la editorial Siruela una antología de relatos sobre el tema de la ondina en la que figuran los más representativos del romanticismo alemán -"La ninfa de la fontana" de Musäus, la "Ondina" de La Motte-Fouqué, "La nixa del estanque" de los hermanos Grimm y "La historia de la bella Lau" de Mörike-, y del romanticismo español: "La ondina del lago azul" de Avellaneda y "Los ojos verdes" de Bécquer. 
leitmotif tanto de La dama de Amboto de Avellaneda como de El monte de las ánimas de Bécquer (1987: 263); la flor que nace justo donde alguien pierde su amor aparece en La flor del ángel de Avellaneda y en La rosa de pasión de Bécquer; El aura blanca de Avellaneda presenta también ciertas semejanzas con La corza blanca de Bécquer, lo mismo que ocurre entre $E l$ donativo del diablo y la becqueriana La cruz del diablo, y estas semejanzas son aún mayores entre La ondina azul y Los ojos verdes (1987: 265-266). Rexach parece desconocer el artículo de Gulsoy, publicado veinte años antes, porque cuando se refiere a las coincidencias entre estas dos leyendas sólo cita a Myron I. Lichtblau y María A. Salgado. Lichtblau estudió en 1981 La velada del helecho de Avellaneda y en la parte introductoria de dicho estudio alude a la escritora cubana como antecesora de Bécquer: "Como escritora de leyendas, ella es contemporánea del Duque de Rivas y de Zorrilla, y un digno antecesor de Bécquer" (1981: 329). En cuanto a María A. Salgado, su referencia al tema es también tangencial y muy breve: "Efectivamente, "La ondina", elaborada sobre el mismo tema de "Los ojos verdes" de Bécquer, es una joya del género" (1981: 344).

Pues bien, a pesar de que tantas leyendas becquerianas tengan ecos de las de Avellaneda, a pesar de que cuando Bécquer llega a Madrid la cubana sea ya "una figura harto conocida tanto literaria como socialmente", a pesar de frecuentar ambos las veladas musicales organizadas por el padre de Julia Espín, como atestigua Julio Nombela, y a pesar de que tuvieron amigos comunes, entre ellos Ramón Rodríguez Correa, que también era cubano, Rexach advierte con sorpresa que "en ningún momento en las páginas que escriben uno y otra se nombran, ni siquiera se aluden” (1987: 264):

Confieso que vivo hace años intrigada por este silencio. Una sola vez que yo sepa es mencionada la Avellaneda en relación con el poeta sevillano, $\mathrm{y}$ esto para quitarle importancia al hecho inmediatamente. El testimonio es de Nombela. Dice: “En casa de don Joaquín Espín Guillén se celebraban veladas musicales y literarias a las que acudían Gertrudis Gómez de Avellaneda (que nunca coincidiría con Bécquer, pues regresó a Cuba en 1859 para volver a España en 1863), Gaspar Núñez de Arce, Tamberlick, los Romea...". Debe destacarse que tanto el poeta como su hermano Valeriano fueron introducidos en dicho círculo por Ramón Rodríguez Correa, cubano y amigo de la Avellaneda. ¿A qué se debe, entonces, ese pertinaz silencio que hasta hoy nadie ha logrado romper" (1987: 264). 
A Rexach esta circunstancia le parece muy extraña, habida cuenta de que Bécquer ejerció durante un tiempo como cronista teatral y Avellaneda consiguió por aquellos años gran notoriedad gracias al éxito de dos de sus obras dramáticas, Saúl y Baltasar, que sí reseñaron los amigos de Bécquer, en concreto Julio Nombela:

(...) ¿cómo se explica que Bécquer, a la sazón cronista teatral, jamás nombre a la Avellaneda en sus crónicas de ese tiempo, cuando fue entonces que ella alcanzó su mayor fama literaria con "Saúl" y, sobre todo, con "Baltasar". Porque hay otro dato. Cuando "Baltasar" se estrena lo comenta ampliamente Julio Nombela (1987: 266).

Rexach acude entonces a la biografía de Rica Brown, y pone al día las sospechas de la estudiosa norteamericana sobre la existencia de una misteriosa mujer, entre Julia y Casta, que habría inspirado en el poeta una honda pasión y que sería la verdadera musa de las Rimas. Pues bien, Rexach aventura la posibilidad de que dicha mujer sea Gertrudis Gómez de Avellaneda:

Estamos tocando aquí la piel de un misterio que sólo apunto. Tal vez algún día cuando la investigación de la prensa periódica sea más exhaustiva, cuando las nuevas técnicas de archivo de datos y noticias sea más completa y fácil de manejar, cuando se descubran documentos de Bécquer -hoy al parecer perdidos- y quizá otros de la Avellaneda salgan a la luz, gran parte de ese misterio quede esclarecido. Por lo pronto ahí está ese misterio de las cartas de Bécquer quemadas por el poeta dos días antes de morir y queda la extraña coincidencia entre las leyendas. Por ahí debe continuar la investigación (1987: 267).

Por más que la hipótesis de Rexach resulte atractiva, no deja de ser otra ficción en torno a la figura de Bécquer, fruto de una lectura biográfica de las Leyendas, ficción que tiene además la virtud de nublar, de difuminar, con la sugerente historia del romance, la más que evidente influencia de las narraciones de Gertrudis Gómez de Avellaneda sobre Bécquer. Rexach no ha de esforzarse, como hiciera Gulsoy, en afear los aparentes yerros de Avellaneda con el fin de que brillen más los dudosos aciertos de Bécquer. A Rexach le basta con convertir a Avellaneda en la amante de Bécquer para robarle, probablemente sin pretenderlo, el mérito de ser la principal fuente de las leyendas becquerianas, para escatimarle el honor de que quien aca- 
baría convertido en el más célebre escritor de la segunda mitad del XIX la haya imitado claramente.

El becquerianismo se ha valido de diversas estrategias de lectura para pasar de puntillas por esta imitación. Una de las más efectivas quizás haya sido la relación erudita de fuentes del tema de la ondina en otras literaturas, porque la constatación de la existencia de una larga tradición previa permite eludir la confrontación directa entre el relato de Avellaneda y el de Bécquer, que no serían sino los últimos eslabones de dicha tradición, y sobre todo permite obviar la precedencia cronológica de La ondina del lago azul sobre Los ojos verdes. Pero incluso cuando dicha precedencia se ha admitido, cuando se ha hablado abiertamente del influjo de La ondina del lago azul sobre Los ojos verdes, la figura de Bécquer ha brillado más en el Olimpo literario que la de Avellaneda, y lo ha hecho porque los exegetas de la obra del sevillano han tenido buen cuidado de proclamar una y otra vez que Bécquer supera ampliamente a su modelo, que lo mejora. Los criterios empleados para pronunciar semejante juicio esconden, como hemos visto, prejuicios contra las mujeres. No en vano quienes se valen de ellos intentan a toda costa que el protagonista masculino de la leyenda quede en buen lugar, que aparezca como un idealista y no como el iluso que se deja engañar, que es el blanco de las burlas femeninas. La preferencia que Gulsoy muestra por la mujer fantasmal de Bécquer y por la ambientación medieval, frente a la dama real y al tiempo presente del relato de Avellaneda, aunque él la fundamenta arguyendo que así la historia es más poética, en realidad oculta el deseo vehemente de que el prototipo masculino romántico del soñador, del idealista, lo sea efectivamente, que nadie lo pueda tildar de estúpido por culpa de una mujer. Mucha precaución habrá que tener en consecuencia cuando se hable de lo poético, y sobre todo del héroe romántico que lo encarna, porque bajo la máscara del idealismo se puede estar encubriendo, como sucede en este caso, una manifiesta prevención contra las mujeres. Quizás Avellaneda, consciente de ello, intentó efectivamente poner en solfa dicho estereotipo masculino, como ha apuntado la crítica feminista, al desvelar la identidad real de su ondina. Por otra parte, hablar de relaciones amorosas de la Avellaneda y Bécquer, es decir, llevar el tema de las influencias al terreno de la biografía sentimental, acaba nublando dicha influencia, y no contribuye en absoluto al proceso de canonización de las escritoras. Al contrario, las convierte en objetos de deseo de sus colegas 
literarios, las devuelve al ámbito del romance, de los escarceos amorosos, y de ese modo las empequeñece, las reduce al papel tradicional de la dama impasible, inalcanzable, que se les adjudicó tempranamente a las mujeres en la literatura cortés, un papel que el romanticismo transmutaría en mujer fantasmal y luego el psicoanálisis redefiniría a partir de los términos de $p a-$ sividad y narcisismo. Avellaneda, cuyas leyendas Bécquer ha emulado, no lo perdamos de vista, una vez convertida en la amante misteriosa y esquiva, una vez leída a partir del modelo romántico de la mujer fantasmal, pierde todas sus prerrogativas literarias sobre quien pudo haber sido su discípulo, pierde incluso, y esto es lo más importante, su condición de escritora, para ser simplemente otro de los espectros femeninos que recorren la obra del sevillano.

\section{Referencias}

Albin, M. C. (1995). Álbum Cubano de Gómez de Avellaneda: la esfera pública y la crítica a la modernidad. Cincinnati Romance Review, XIV, 73-79. . (2000). Fronteras de género, nación y ciudadanía: La Ilustración. Álbum de las damas (1845) de Gertrudis Gómez de Avellaneda. En F. Sevilla y C. Alvar (eds.), Actas del XIII Congreso de la Asociación Internacional de Hispanistas (pp. 67-75). Madrid: Castalia, II. . (2002). Género, poesía y esfera pública. Gertrudis Gómez de Avellaneda y la tradición romántica. Madrid: Editorial Trotta. . (2007). El costumbrismo feminista de Gertrudis Gómez de Avellaneda. Anales de Literatura Hispanoamericana, 36, 159-170.

Arriaga Flórez, M. (2001). Mi amor, mi juez. Alteridad autobiográfica femenina. Barcelona: Anthropos.

Ayala, M. A. (1998). Dos mujeres, novela reivindicativa de Gertrudis Gómez de Avellaneda. En D. Flitter (ed.), Actas del XII Congreso de la Asociación Internacional de Hispanistas (pp. 76-83). Birmingham: Department of Hispanic Studies, University of Birmingham, IV.

. (2006). Amor y erotismo en La ondina del lago azul, de Gertrudis Gómez de Avellaneda. En Romanticismo 9. El eros romántico. Actas del IX Congreso del Centro Internacional de Estudios sobre el Romanticismo Hispánico "Ermanno Caldera" (pp. 13-23). Bolonia: II Capitello del Sole.

Barreto, R. (2006). Subversion in Gertrudis Gómez de Avellaneda's Sab. Decimonónica, 3 (1): 1-26.

Bécquer, G. A. (1995). Obras completas. Edición y prólogo de Ricardo Navas Ruiz. Madrid: Turner. 
Benítez, R. (1971). Bécquer tradicionalista. Madrid: Gredos. . (1974). Introducción. Las leyendas de Bécquer. Tradición y originalidad. En G. A. Bécquer. Leyendas, apólogos y otros relatos (pp. 7-53). Barcelona: Labor.

Brown, R. (1963). Gustavo Adolfo Bécquer en dos tiempos. Prólogo de Vicente Aleixandre. Barcelona: Aedos.

Carlos, A. J. (1968). La Avellaneda y la mujer. En C. H. Magis (coord.), Actas del III Congreso Internacional de Hispanistas (pp. 187-193). México D. F.: El Colegio de México.

Catelli, N. (1991). El espacio autobiográfico. Barcelona: Lumen.

Catena, E. (1989). Introducción. En Gertrudis Gómez de Avellaneda. Poesía y epistolario de amor y amistad (pp. 7-35). Madrid: Castalia.

Cotarelo y Mori, E. (1928-1930). La Avellaneda y sus obras. Ensayo biográfico y crítico. Boletín de la Real Academia Española, Tomo XV, Cuaderno LXXV, diciembre de 1928, pp. 583-635; Tomo XVI, Cuaderno LXXVI, febrero 1929, pp. 5-48; Cuaderno LXXVII, abril de 1929, pp. 131-184; Cuaderno LXXVIII, junio de 1929, pp. 267-325; Cuaderno LXXIX, octubre de 1929, pp. 395-437; Cuaderno LXXX, diciembre de 1929, pp. 529-593; Tomo XVII, Cuaderno LXXXI, febrero de 1930, pp. 5-71; Cuaderno LXXXII, abril de 1930, pp. 145-205 $5^{17}$.

Cueto, L. A. (1871). Observaciones acerca de algunas leyendas y novelas de la señora doña Gertrudis Gómez de Avellaneda. En G. Gómez de Avellaneda, Obras literarias de la Señora Doña Gertrudis Gómez de Avellaneda (pp. 397-414). Madrid: Imprenta y Estereotipia de M. Rivadeneyra, Tomo V.

Esteban, A. (2007). Introducción. En G. A. Bécquer. Todas las narraciones (pp. 11-74). Palencia: Ediciones Cálamo.

Ezama Gil, A. ( 2011). Los relatos de viaje de Gertrudis Gómez de Avellaneda. Anales de Literatura Española, 23, 323-351.

Fernández, T. (2014). De pasiones imaginarias: la narrativa de Gertrudis Gómez de Avellaneda. Arbor, 190 (770), a185.

Ferrús Antón, B. (2003). El yo imposible: Gertrudis Gómez de Avellaneda y la escritura autobiográfica. En: J. C. Rovira Soler (ed.), Con Alonso Zamora Vicente "b": Actas del Congreso Internacional "La Lengua, la Academia, lo Popular, los Clásicos, los Contemporáneos” (pp. 601-608). Alicante: Universidad de Alicante, II.

. (2004). Destinos de mujer. Tres novelas románticas de Gertrudis Gómez de Avellaneda. Cuadernos de Ilustración y Romanticismo: revista del Grupo de Estudios del siglo XVIII, 12, 3-15.

Gómez de Avellaneda, G. (2000). Baltasar. La hija de las flores. Ed. María

${ }^{17}$ Cotarelo publicó poco después esta serie de artículos en el volumen La Avellaneda y sus obras. Ensayo biográfico y crítico (1930). 
Prado Más. Madrid: Publicaciones de la Asociación de Directores de Escena de España.

. (2008). Errores del corazón y otras comedias. Ed. Concha Fernández Soto. Sevilla: Arcibel.

González Subías, J. L. (2005). Gertrudis Gómez de Avellaneda y la tragedia romántica española. En L. F. Díaz Larios, V. Trueba, E. Rubio, P. Miret, J.F. Botrel y L. Bonet (eds.), Lectora, Heroína, Autora (La mujer en la literatura española del siglo XIX). III Coloquio de la Sociedad de Literatura Española del Siglo XIX (pp. 173-183). Barcelona, 23-25 de octubre de 2002. Barcelona: PPU.

Guerra Cunningham, L. (1985). Estrategias femeninas en la elaboración del sujeto romántico en la obra de Gertrudis Gómez de Avellaneda. Revista Iberoamericana, 51 (132-133), 707-722.

Gulsoy, J. (1967). La fuente común de Los ojos verdes y El rayo de luna de Gustavo A. Bécquer. Bulletin of Hispanic Studies, XLIV, 96-106.

Gutiérrez de la Solana, A. (1981). Sab y Francisco: Paralelo y contraste. En G. Zaldívar y R. Martínez de Cabrera (eds.), Homenaje a Gertrudis Gómez de Avellaneda. Miami: Editora Universal.

Harter, H. A. (1981). Gertrudis Gómez de Avellaneda. Boston: Twayne Publishers.

Kirkpatrick, S. (1989). Las románticas. Escritoras y subjetividad en España. 1835-1850. Madrid: Cátedra/Universidad de Valencia, Instituto de la Mujer, 1991.

. (1990). Gómez de Avellaneda' Sab: Gendering the liberal romantic subject. En N. Valis y C. Maier (eds.), In the Feminine Mode. Essays in hispanic women writers (pp. 115-130). London and Toronto: Associated University Presses.

Lichtblau, M. I. (1981). La leyenda de La velada del helecho: análisis de la técnica narrativa. En G. Zaldívar y R. Martínez de Cabrera (eds.), Homenaje a Gertrudis Gómez de Avellaneda. Memorias del simposio en el centenario de su muerte (pp. 329-337). Miami: Ediciones Universal.

Molina Foix, J. A. (2005). Ondinas: las ninfas del agua. Madrid: Siruela.

Navas Ocaña, I. (2011). Poesía eres tú... pero yo no quiero ser poesía. Madrid: Visor.

Navas Ruiz, R. (1995). Introducción. En G. A. Bécquer. Obras completas (I, pp. IX-XXV y II, pp. IX-XXV). Madrid: Turner.

. (2005). Introducción. En G. A. Bécquer. Libro de los gorriones. Narraciones. Escritos varios (pp. 7-72). Salamanca: Editorial Ambos Mundos.

Pastor, B. (1999). Mujer y transgresión en la prensa cubana del siglo XIX: Álbum cubano de lo bueno y lo bello. Isla de Arriarán, XIX: 325-344.

. (2002). El discurso de Gertrudis Gómez de Avellaneda: identidad femenina y otredad. Murcia: Cuadernos de América sin Nombre. 
. (2004). Fashioning Feminism in Cuba and beyond. The prose of Gertrudis Gómez de Avellaneda. New York: Peter Lang.

Picón Garfield, E. (1992). Periodical literature for women in mid-nineteenthcentury Cuba: The case of Gertrudis Gómez de Avellaneda's Album cubano de lo bueno y lo bello. Studies in Latin America Culture, 11, 13-28.

. (1993). Poder y sexualidad: el discurso de Gertrudis Gómez de Avellaneda. Ámsterdam: Rodopi.

Prado Mas, M. (2001). El teatro de Gertrudis Gómez de Avellaneda. Madrid: Universidad Complutense de Madrid, tesis doctoral.

Rexach, R. (1987). Conexiones entre las leyendas de Bécquer y las de Avellaneda. Las relaciones literarias entre España e Iberoamérica. XXIII Congreso del Instituto Internacional de Literatura Iberoamericana (pp. 259-267). Madrid: Editorial Universidad Complutense. Incluido en Estudios sobre Gertrudis Gómez de Avellaneda. La reina mora del Camagüey (pp. 61-72). Madrid, Editorial Verbum, 1996.

Rodríguez Gutiérrez, M. (2014). Que yo las nubes resistir no puedo: las respuestas de Carolina Coronada y Luisa Pérez de Zambrana ante la polémica en torno al género en Gertrudis Gómez de Avellaneda (una lectura transatlántica). Arbor, 190 (770), a183.

Romero, C. (2014). Gertrudis Gómez de Avellaneda desde otro ápice: su labor como prologuista. Arbor, 190 (770), a189.

Salgado, M. A. (1981). El arte de la leyenda en Gertrudis Gómez de Avellaneda. En G. Zaldívar y R. Martínez de Cabrera (eds.), Homenaje a Gertrudis Gómez de Avellaneda. Memorias del simposio en el centenario de su muerte (pp. 338-346). Miami: Ediciones Universal.

Santos, N. E. (1981). Las ideas feministas de Gertrudis Gómez de Avellaneda. En G. Zaldívar y R. Martínez de Cabrera (eds.), Homenaje a Gertrudis Gómez de Avellaneda (pp. 132-141). Miami: Ediciones Universal.

Saura, A. (2006a). Gertrudis Gómez de Avellaneda, adaptadora teatral. Çédille: revista de Estudios Franceses, 2, 103-113.

. (2006b). Gertrudis Gómez de Avellaneda, traductora de poesía. En F. Lafarga y L. Pegenaute (eds.), Traducción y traductores, del Romanticismo al Realismo (pp. 489-503). Actas del Coloquio Internacional celebrado en la Universidad Pompeu Fabra. Bern: Peter Lang.

Scott, N. M. (1997). Los espíritus tutelares de Avellaneda. Mujeres latinoamericanas: Historia y Cultura. Siglos XVI al XIX (pp. 187-193). La Habana: Casa de las Américas, Tomo II.

Selimov, A. (2014). El amor, el destino y la virtud: Gertrudis Gómez de Avellaneda y su primer drama Leoncia. Arbor, 190 (770), a187.

Suárez-Galbán, E. (1980). La angustia de una mujer indiana, o el epistolario autobiográfico de Gertrudis Gómez de Avellaneda. L'autobiographie dans le monde hispanique. Actes du Colloque International de la Baume-lès- 
Aix (pp. 281-296). Aix-en-Provence: Centre de Recherches Hispaniques de l’Université de Provence.

Torras, M. (2003). Soy como consiga que me imaginéis. La construcción de la subjetividad en las autobiografías epistolares de Gertrudis Gómez de Avellaneda y Sor Juana Inés de la Cruz. Cádiz: Universidad de Cádiz.

Varela Jácome, B. (1997). Función de lo fantástico en dos leyendas de Gómez de Avellaneda. En J. Pont (ed.), Narrativa fantástica en el siglo XIX (España e Hispanoamérica) (pp. 107-118). Lleida: Editorial Milenio. En B. Varela Jácome, Asedios a la literatura cubana. Textos y contextos (pp. 67-84). Santiago de Compostela: Universidad de Santiago de Compostela.

Vega Rodríguez, M. P. (2009). Todas las hadas tienen su lago: geografía fantástica de la leyenda literaria en el Romanticismo español. Belphégor, VIII, 2. 